\title{
Produção de biomassa e óleo essencial de alecrim (Rosmarinus officinalis L.) em função da altura e intervalo entre cortes
}

\author{
MAY,A. ${ }^{1}$; SUGUINO, E. ${ }^{2 *}$; MARTINS, A.N. ${ }^{3}$; BARATA, L.E.S. ${ }^{4}$ PINHEIRO, M.Q. ${ }^{5}$ \\ ${ }^{1}$ Hortec Tecnologia de Sementes Ltda, Rua da Liberdade, 334. Jardim Santa Rita de Cássia, CEP: 12914-071, \\ Bragança Paulista-Brasil mayandre@bol.com.br ${ }^{2} A P T A / S A A, A v$. Bandeirantes, 2419, CEP: 14030-670, Ribeirão \\ Preto-Brasil *esuguino@apta.sp.gov.br ${ }^{3}$ APTA/SAA Médio Paranapanema, Rodovia SP 333 (Assis-Marília) km \\ 397, CEP: 19800-000, Assis-Brasil adrianamartins@apta.sp.gov.br ${ }^{4}$ Instituto de Química, UNICAMP, Caixa \\ Postal 6154, CEPP: 13083-970, Campinas-Brasil Ibarata@iqm.unicamp.br ${ }^{5}$ Rua Germania, 270, CEP: 13070- \\ 770, Campinas-Brasil marianeqp@gmail.com
}

\begin{abstract}
RESUMO: O alecrim é planta exótica e o interesse no seu cultivo tem crescido ao longo dos anos, pois pode ser utilizado tanto para fins medicinais como aromáticos; no entanto, o conhecimento fitotécnico sobre a espécie é bastante limitado. Dessa forma, o trabalho objetivou avaliar a influência da altura de corte e do intervalo destes sobre a produção de biomassa e no rendimento do óleo essencial de alecrim. O experimento foi realizado no Instituto Agronômico, em Campinas - SP, no período de janeiro de 2006 a julho de 2007. O delineamento experimental utilizado foi em blocos ao acaso, com 8 tratamentos em esquema fatorial $2 \times 4$, sendo duas alturas de corte $(20$ e $40 \mathrm{~cm}$ ) e quatro intervalos entre cortes $(60,80,100,120$ dias) e três repetições. Foram avaliadas as características altura da planta, massa seca da parte aérea, rendimento e qualidade do óleo essencial. Observou-se que maiores intervalos entre cortes proporcionaram maior altura da planta e maior massa seca da parte aérea. $O$ rendimento e a qualidade do óleo essencial não foram afetados ao longo do período experimental.
\end{abstract}

Palavras-chave: altura de corte, intervalo entre cortes, manejo cultural, plantas medicinais, planta aromática

\begin{abstract}
Biomass production and essential oil of rosemary (Rosmarinus officinalis L.) in function of the height and interval between the cuts. Rosemary is an exotic plant and the interest in its cultivation has been growing along the years, because it can be used for medicinal or aromatic ends, however the agricultural knowledge about the species is quite limited. The goal of this research was to evaluate the influence of the cutting height and of the interval of these cuts on the biomass production and on the yield of the rosemary essential oil. The experiment was conducted at the Agronomical Institute, in Campinas - SP, from January 2006 through July 2007. It was organized in a completely randomized design with 8 treatments in a $2 \times 4$ factorial system, with two cutting heights (20 and $40 \mathrm{~cm}$ ) and four intervals between cuts $(60,80,100,120$ days) and three replications. Characteristics such as plant height, dry mass of the aerial part, yield and quality of its essential oil were evaluated. It was observed that longer intervals among cuttings provided longer height of the plant and greater dried mass of the aerial part. The yield and the quality of the essential oil were not affected throughout the experimental period.
\end{abstract}

Key words: cutting height, cutting gap, crop management, medicinal plants, aromatic plant

\section{INTRODUÇÃO}

O alecrim (Rosmarinus officinalis L.) é planta pertencente à família Lamiaceae (Labiatae), originária do Sul da Europa e do Norte da África (Martins et al., 1998). É também conhecido pelos nomes populares de alecrim-da-horta, alecrim-de jardim, alecrim-decheiro, alecrim-rosmarinho, roris marino (latim), rosemary (inglês), romero (espanhol), romarin (francês), ramerino (italiano), rosmarin (alemão). De acordo com relatos encontrados na literatura, esta planta pode apresentar propriedades estomacais, estimulantes, antiespasmódica, emenagogas e cicatrizantes. 
É subarbusto muito ramificado, sempre verde, com hastes lenhosas, folhas pequenas, sésseis, finas, opostas e lanceoladas, de sabor picante. A parte inferior das folhas é de cor verdeacinzentada, enquanto a superior é quase prateada. A planta exala aroma forte e agradável. Utilizada com fins culinários, medicinais e aromáticos, sendo o óleo essencial utilizado em cosméticos e perfumaria (Martins et al., 2000).

As propriedades antioxidantes do extrato de alecrim têm recebido atenção especial nos últimos anos, sendo reconhecidas desde a Antiguidade (Porte \& Godoy , 2001).

O óleo essencial de alecrim é muito utilizado nas indústrias cosméticas, de higiene e perfumaria na fabricação de sabonetes, shampoos, desodorantes, colônias e desinfetantes (Robbins \& Greenhalgh, 1979). Além disso, o extrato alcoólico dessa planta tem uso como antioxidante na indústria alimentícia (Zegarska et al., 1996).

A composição dos óleos essenciais das plantas é determinada pela espécie, variedade, período de colheita e tipo de processamento (Guillén et al., 1996).

Segundo Scheffer (1992), são necessários estudos que revelem o comportamento de espécies medicinais em geral, pois como são poucas as informações agronômicas disponíveis. Não se sabe, por exemplo, se estas plantas quando submetidas às técnicas de produção de biomassa por área, não tenham seu valor terapêutico afetado, visto que a síntese desses compostos medicinais pode sofrer alterações de acordo as técnicas de cultivo.

O manejo da cultura é determinante na produção de folhas e óleo essencial. Czepak (1995) estudando a influência do intervalo entre cortes em Mentha arvensis $\mathrm{L}$. verificou que colheitas realizadas a cada 60,70 e 90 dias após o plantio proporcionaram maior volume de óleo ao longo de um ano de colheitas.

Mol et al. (2002), estudando carqueja (Baccharis trimera DC.), observaram que a colheita não deveria ser realizada por meio de cortes na altura do colo, sendo mais indicada a altura de $10 \mathrm{~cm}$.

As informações sobre o cultivo e manejo cultural do alecrim são escassas. Dessa forma, o trabalho objetivou avaliar a influência da altura de corte e do intervalo entre cortes sobre a produção de biomassa e no rendimento do óleo essencial de alecrim.

\section{MATERIAL E MÉTODO}

$\mathrm{O}$ experimento foi realizado no Instituto Agronômico (IAC), em Campinas - SP, no Centro de Análise e Pesquisa Tecnológica do Agronegócio de Horticultura, no período de janeiro de 2006 a julho de 2007.
O delineamento experimental utilizado foi em blocos ao acaso, com três repetições, com os tratamentos em esquema fatorial $2 \times 4$, sendo duas alturas de corte (20 e $40 \mathrm{~cm}$ ) e quatro intervalos entre os cortes (60,80,100, 120 dias).

O material genético utilizado foi coletado no banco de germoplasma de Plantas Aromáticas e Medicinais do IAC, provenientes de plantas com dois anos de idade, cuja exsicata, presente no Herbário do IAC, é mantida pelo número 8126.

Para produção de mudas foram utilizadas estacas apicais herbáceas com $8 \mathrm{~cm}$ de comprimento, enraizadas em bandejas de poliestireno expandido com 200 células, contendo substrato Plantmax®. As bandejas contendo as estacas foram acondicionadas em casa de vegetação com sistema de irrigação e nebulização própria para a propagação de plantas.

A análise do solo na profundidade de 0 a 0,2 $\mathrm{m}$ foi feita no Laboratório de Análise de Solo do Instituto Agronômico, e revelou pH em $\mathrm{CaCl}_{2}$ de $4,4 \mathrm{e}$ $28 \mathrm{~g} \mathrm{dm}^{-3}$ de matéria orgânica, e $22 \mathrm{mg} \mathrm{dm}^{-3}$ de Presina. Os teores de $\mathrm{K}, \mathrm{Ca}, \mathrm{Mg}, \mathrm{H}+\mathrm{Al}$ foram, respectivamente, 1,$0 ; 14 ; 6$ e $64 \mathrm{mmol}_{\mathrm{c}} \mathrm{dm}^{-3}$ e a CTC efetiva igual a $85,4 \mathrm{mmol}_{\mathrm{c}} \mathrm{dm}^{-3}$, segundo metodologia descrita por Van Ray et al. (2001).

A calagem foi realizada em função da análise de solo, antes das operações de aração e gradagem, visando elevar a $70 \%$ a saturação por bases.

O sistema de irrigação utilizado foi o de gotejamento. As irrigações foram diárias durante as primeiras semanas após o transplantio das mudas para o campo, até o enraizamento das mesmas, e semanalmente em complementação às precipitações pluviais, nos períodos subseqüentes, com a aplicação de uma lâmina média de $10 \mathrm{~mm}$.

O espaçamento utilizado foi de $0,5 \mathrm{~m}$ entre linhas por 0,4 $\mathrm{m}$ entre plantas. Cada parcela continha cinco linhas de plantio com quatro metros de comprimento, totalizando quarenta plantas por parcela, sendo avaliadas as dezoito plantas centrais de cada parcela.

Aos 150 dias após o plantio, foi realizado corte manual de uniformização em todas as parcelas. Esta data foi definida como sendo a inicial para a característica "Intervalo entre cortes".

Ao longo do período experimental foram realizados cinco, quatro, três e dois cortes, respectivamente, para os intervalos entre cortes de 60, 80, 100 e 120 dias.

Em cada corte foram avaliadas as características altura da planta, massa seca da parte aérea, rendimento e qualidade do óleo essencial.

A altura da planta foi determinada pela medição da distância entre o nível do solo e a extremidade superior da planta, expressa em centímetros $(\mathrm{cm})$. 
A secagem da parte aérea foi realizada em estufa de circulação forçada de ar quente a $65^{\circ} \mathrm{C}$ por $96 \mathrm{~h}$, até atingir massa constante.

Para estudo da influência dos fatores na produção de massa seca, foi somada a massa seca da parte aérea ao longo do ciclo da cultura em cada tratamento, segundo o intervalo entre cortes estabelecido, resultando na massa seca acumulada, expressa em tha-1.

De cada tratamento nas datas de corte, 150 $\mathrm{g}$ de parte aérea da planta fresca passavam por destilações realizadas em destilador Clevenger modificado pelo período de 2 horas (Clevenger, 1928).

A composição química dos óleos essenciais foi quantificada em cromatógrafo a gás acoplado a espectrômetro de massas (CG-EM, Shimadzu QP5000), com ionização por elétrons $(70 \mathrm{eV})$, dotado de coluna capilar DB-5 (30 m x 0,25 mm x 0,25 $\mu \mathrm{m})$, hélio como gás de arraste $\left(1,0 \mathrm{~mL} \mathrm{~min}^{-1}\right)$, injetor a $240^{\circ} \mathrm{C}$ e detector a $230^{\circ} \mathrm{C}$. Os óleos essenciais foram solubilizados em acetato de etila (PA, Merck, $5 \mathrm{mg}$ óleo $\mathrm{mL}^{-1}$ solvente), injetado $1 \mathrm{~mL}$ de solução, split:1/ 20 e programa de temperatura igual a $60^{\circ} \mathrm{C}-280^{\circ} \mathrm{C}$ a $3^{\circ} \mathrm{C}$ por minuto. As substâncias foram identificadas pela comparação dos espectros de massas com o banco de dados do CGEM (Nist 62.lib) e índice de retenção (Adams, 1995).

Os resultados obtidos foram submetidos à análise de variância utilizando-se o programa estatístico ESTAT (UNESP-FCAV, Campus Jaboticabal) e, quando houve significância pelo teste de F, aplicou-se teste de Tukey $(p \leq 0,05)$ e regressão polinomial. Os modelos de regressão foram selecionados pelo maior coeficiente de determinação $\left(R^{2}\right)$ que tenha apresentado maior significância pelo teste $\mathrm{F}$.

\section{RESULTADO E DISCUSSÃO}

Não houve interação significativa $(p>0,05)$ entre os fatores altura de corte e intervalo entre corte para a característica massa seca da parte aérea. Apenas houve efeito significativo isolado do fator intervalo entre cortes para essa característica avaliada.

Foram observados incrementos lineares na produção da massa seca da parte aérea com o aumento no intervalo entre cortes, passando de 3,95 para $8,39 \mathrm{t} \mathrm{ha}^{-1}$ de massa seca, respectivamente para os intervalos 60 e 120 dias entre cortes, o que representou aumento de $112 \%$ na massa seca produzida ao longo do período experimental (Figura 1).

Maiores produtividades de biomassa com intervalos entre cortes menores podem ser importantes para redução dos custos operacionais da cultura, já que o uso de mão de obra para a colheita é menor, resultando em produtividades superiores.

Corrêa Júnior et al. (1994) citam que a faixa de produção anual de massa seca de folhas de alecrim é de 1,6 a 2,4 $\mathrm{t} \mathrm{ha}^{-1}$. Considerando que a porcentagem de folhas na massa seca da parte aérea é de $70 \%$, a faixa de produção estimada anual de massa seca da parte aérea pode ser de 2,3 a 3,4 t ha $^{-1}$.

Dessa forma, a produção de biomassa alcançada nesse experimento, 8,39 $\mathrm{t} \mathrm{ha}^{-1}$ de massa seca da parte aérea com cortes a cada 120 dias, pode ser considerada elevada.

Considerando que foram realizados cinco, quatro, três e dois cortes ao longo do período experimental para os intervalos de 60, 80, 100 e 120 dias, respectivamente, a produção de biomassa em cada avaliação elevou-se, gradativamente, quanto

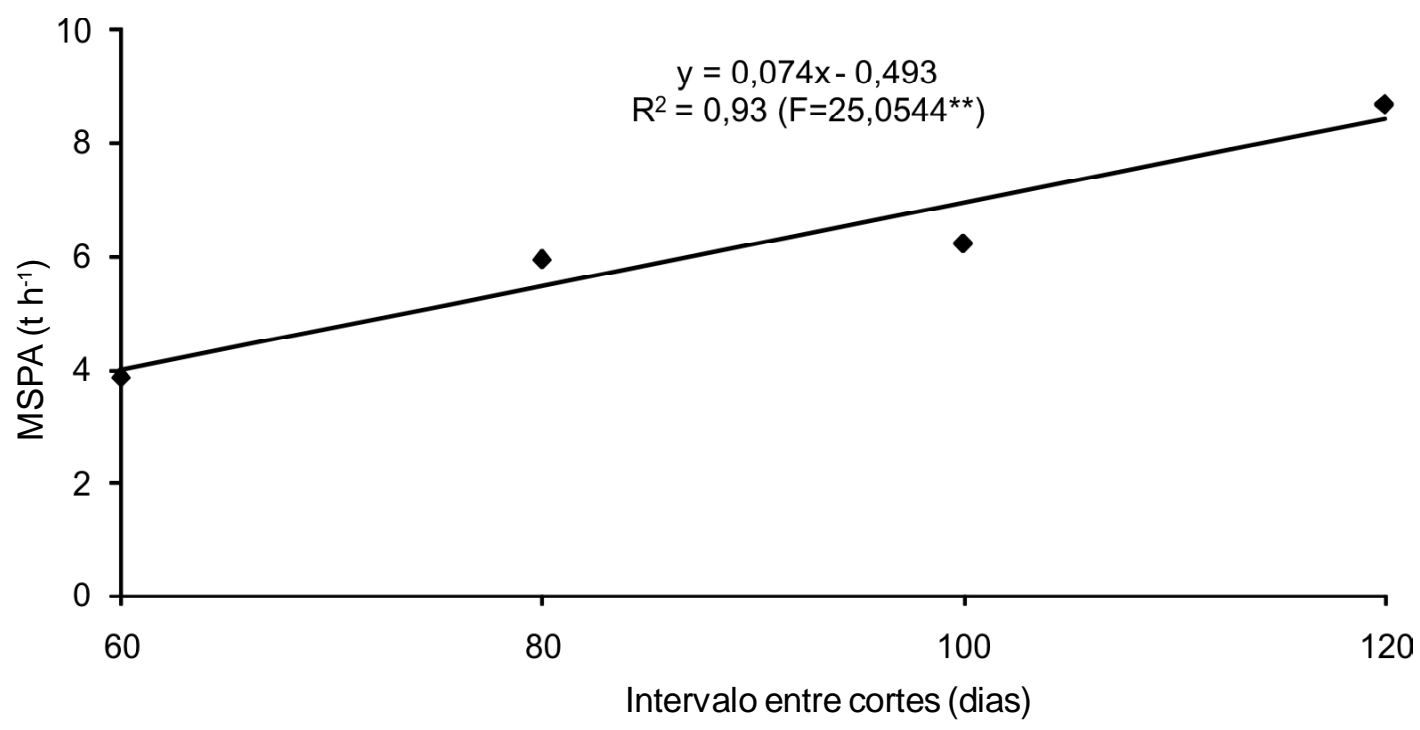

FIGURA 1. Influência do intervalo entre cortes sobre a massa seca da parte aérea (MSPA) de Rosmarinus officinalis $\mathrm{L}$.

Rev. Bras. PI. Med., Botucatu, v.12, n.2, p.195-200, 2010. 
maior fosse o intervalo, apresentando valores de 789,4, $1356,7,2302,3$ e 4193,5 $\mathrm{kg} \mathrm{ha}^{-1}$ de massa seca para cada intervalo estudado. Este fato demonstrou a menor capacidade produtiva da planta submetida a condições de cortes mais freqüentes, caracterizado pelo menor período de recuperação da planta (menor intervalo entre cortes).

Nas condições experimentais dessa pesquisa, visando maiores produções de biomassa vegetal, as plantas de alecrim necessitaram de período de recuperação prolongado, demonstrando que cortes intensivos gradativos (menores intervalos entre cortes) podem exaurir a planta, reduzindo a capacidade de resposta produtiva das mesmas ao longo do tempo.

Houve efeito significativo isolado para os fatores estudados para a característica altura da planta.

Observou-se maior altura da planta para a maior altura de corte estudada, apresentando valores de 76,0 e 62,7 cm, respectivamente, para o corte a 40 e $20 \mathrm{~cm}$, e apesar da diferença de $13,2 \mathrm{~cm}$ entre as plantas, a produção de biomassa entre as duas alturas de corte estudadas não foi alterada.

Houve incremento linear na altura da planta com o aumento do intervalo entre cortes estudado, passando de $55 \mathrm{~cm}$ para $83,4 \mathrm{~cm}$, respectivamente para intervalos entre cortes de 60 e 120 dias.

Assim, o incremento na altura da planta, com o aumento do intervalo entre cortes estudado, acarretou no aumento da massa seca da parte aérea produzida, conforme se observa na Figura 2.

Cruz et al. (2001), com objetivo de determinar a altura e o número de cortes em alfavaca-cravo (Ocimum gratissimum L.), concluíram que a combinação do adensamento de plantio, com cortes em intervalos de 45 dias, iniciando aos 120 dias de idade, e a altura de corte a $30 \mathrm{~cm}$ do solo proporcionaram as maiores produção de biomassa e óleo essencial. Dessa forma, a maior produção de biomassa foi obtida com a altura de corte mais alta, provavelmente, em virtude da maior velocidade de rebrota ocorrida devido ao grande número de gemas remanescentes nessa situação.

Não houve efeito significativo $(p>0,05)$ dos fatores estudados sobre a característica rendimento do óleo essencial. Considerando que o rendimento médio de óleo essencial na massa fresca foi de $0,75 \%$ e a produção máxima de biomassa seca de $8,39 \mathrm{t}$ ha $^{-1}$ (intervalo entre cortes de 120 dias), correspondendo a $42 \mathrm{t} \mathrm{ha}^{-1}$ de massa fresca (considerando-se a porcentagem de $20 \%$ de massa seca), estima-se que rendimento de óleo essencial foi em torno de $315 \mathrm{~kg} \mathrm{ha}^{-1}$.

Czepak (1995) obteve maior produção de óleo essencial de Mentha arvensis, por área cultivada com menores intervalos entre cortes, sendo $338 \mathrm{~L} \mathrm{ha}^{-1}$ ano-1 $^{-1}$ para 60 dias, em razão da maior massa seca da parte aérea anual obtida com menor intervalo entre cortes, $4000 \mathrm{~kg} \mathrm{ha}^{-1} \mathrm{ano}^{-1}$.

Chalchat et al. (1993) compararam a composição dos principais constituintes dos óleos essenciais de alecrim provenientes de várias origens de países de maior produção, sendo os constituintes encontrados em maior teor: 1,8 cineol (41,1 a 58\%, no Marrocos; 40,1 a 44,4\%, na Tunísia; 17,0 a 25,1\%, na Espanha e 24,8\% na França), alfa-pineno (2,7 a 12\%, no Marrocos, 1,6 a 10,3\%, na Tunísia, 4,0 a 19,1\%, na Espanha e 19,0 a 35,0\%, na França) e cânfora (7,4 a 13,5\%, no Marrocos, 9,9 a 12,5\%, na Tunísia, 10,0 a 20,7\%, na Espanha e 3,0 a 7,5\%, na França).

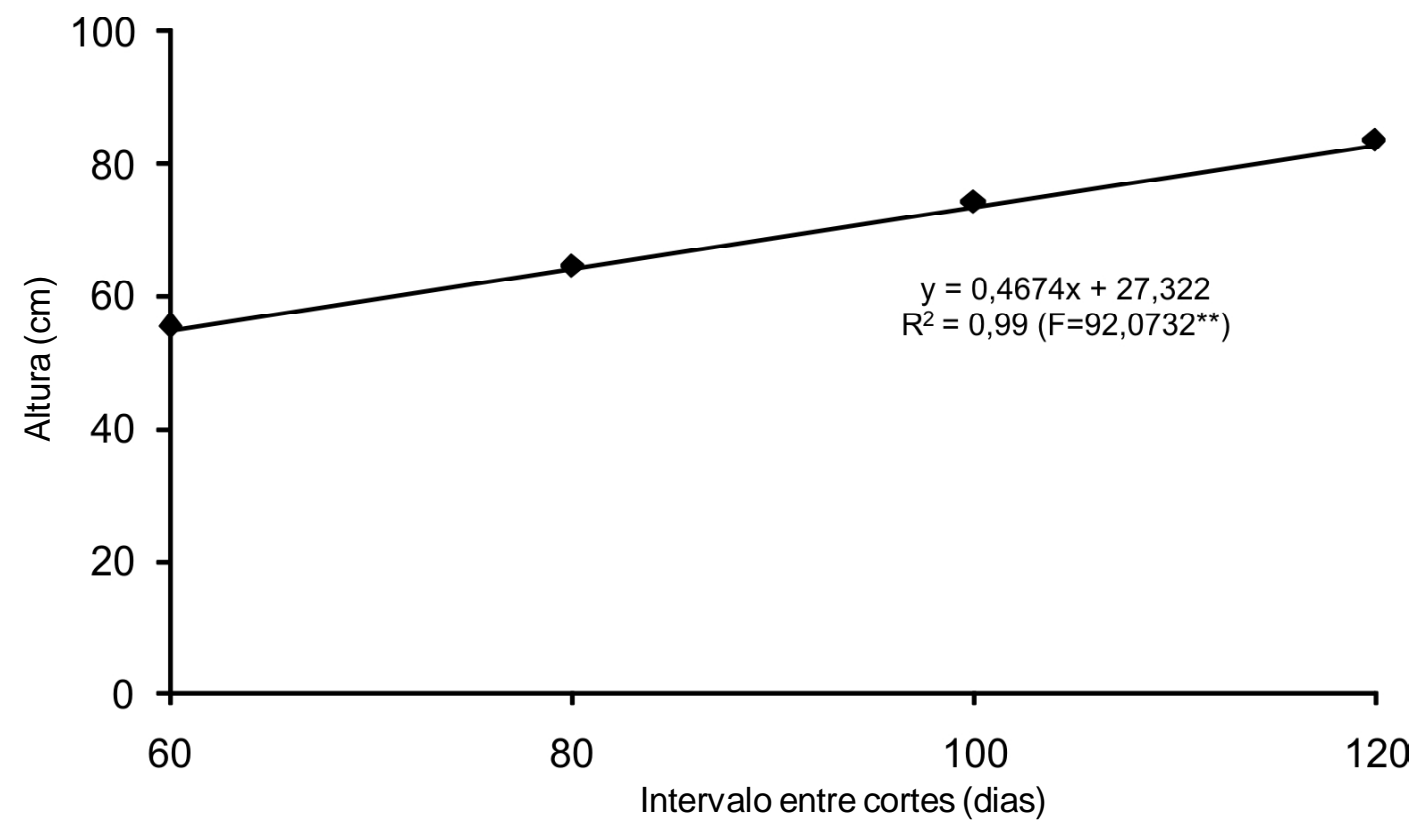

FIGURA 2. Influência do intervalo entre cortes sobre a altura da planta (Rosmarinus officinalis L). 
TABELA 1. Valores dos principais componentes do óleo essencial de alecrim em função do intervalo entre corte estudado, expressos em porcentagem.

\begin{tabular}{ccccccccccc}
\hline $\begin{array}{c}\text { Intervalo } \\
\text { entre } \\
\text { cortes }\end{array}$ & $\begin{array}{c}\text { Número } \\
\text { do } \\
\text { corte }^{1}\end{array}$ & $\begin{array}{c}\text { Alfa- } \\
\text { pineno }\end{array}$ & $\begin{array}{c}\text { Beta - } \\
\text { pineno }\end{array}$ & Mirceno & Limoneno & $\begin{array}{c}1,8- \\
\text { Cineol }\end{array}$ & Cânfora & $\begin{array}{c}\text { Alfa - } \\
\text { terpineol }\end{array}$ & Verbenona & Cariofileno \\
\hline 60 dias & 1 & 10,172 & 4,496 & 8,819 & 3,918 & 12,742 & 23,889 & 2,258 & 3,106 & 5,895 \\
& 2 & 10,321 & 5,561 & 9,094 & 4,191 & 11,767 & 25,004 & 1,841 & 1,281 & 6,537 \\
& 3 & 9,393 & 3,711 & 8,893 & 3,730 & 13,798 & 27,164 & 2,708 & 4,029 & 4,237 \\
& 4 & 10,801 & 4,217 & 8,470 & 3,832 & 12,660 & 23,500 & 2,226 & 3,008 & 4,911 \\
& 5 & 10,342 & 4,321 & 8,847 & 3,830 & 12,760 & 23,888 & 2,258 & 3,001 & 4,923 \\
\hline 80 dias & 1 & 10,981 & 5,365 & 8,338 & 3,739 & 13,836 & 28,403 & 2,129 & 3,830 & 5,329 \\
& 2 & 9,896 & 3,533 & 8,398 & 3,583 & 13,303 & 28,578 & 2,744 & 4,118 & 6,414 \\
& 3 & 10,534 & 4,217 & 8,455 & 3,885 & 13,564 & 27,899 & 2,299 & 4,345 & 4,366 \\
& 4 & 9,987 & 5,565 & 8,344 & 3,566 & 12,894 & 28,302 & 2,389 & 4,502 & 5,348 \\
\hline 100 dias & 1 & 9,426 & 5,224 & 8,943 & 4,207 & 13,070 & 24,022 & 2,096 & 3,008 & 6,005 \\
& 2 & 9,001 & 5,673 & 8,923 & 4,110 & 13,058 & 25,365 & 2,178 & 3,019 & 5,395 \\
& 3 & 9,334 & 5,441 & 8,805 & 4,104 & 13,066 & 24,066 & 2,166 & 3,002 & 5,399 \\
\hline 120 dias & 1 & 10,834 & 4,855 & 8,880 & 3,871 & 12,675 & 28,202 & 2,262 & 3,320 & 4,194 \\
& 2 & 10,862 & 4,500 & 9,578 & 4,085 & 12,897 & 26,276 & 2,358 & 4,345 & 4,695 \\
\hline Média & & 10,135 & 4,763 & 8,771 & 3,904 & 13,006 & 26,040 & 2,279 & 3,422 & 5,261 \\
\hline
\end{tabular}

${ }_{1}^{1}$ Número de cortes realizados ao longo do período experimental, sendo, cinco, quatro, três e dois cortes realizados, respectivamente, para os intervalos entre cortes $60,80,100$ e 120 dias.

Estudos do óleo essencial de Rosmarinus officinalis apresentaram como principais constituintes o 1,8-cineol, cânfora, borneol, acetato de bornila, canfeno, $\alpha$-pineno, $p$-cimeno, mirceno, sabineno, $\beta$ felandreno, $\beta$-pineno, dipenteno e $\beta$-cariofileno (Soliman et al., 1994).

Blanco (2001), estudando a espécie Rosmarinus officinalis em Botucatu/SP, não observou variação no rendimento do óleo essencial entre as estações verão e inverno, contudo verificou pequenas variações nos teores dos componentes do óleo essencial ao longo do ano, apresentando, respectivamente para inverno e verão, valores de 12,30 e 11,24 para alfa-pineno, 11,67 e 10,58 para mirceno, 18,78 e 20,0 para 1,8-cineol, 23,85 para 25,94 para cânfora, 5,35 e 6,58 para cariofileno. Já Porte (2000) observou os teores predominantes no óleo de alecrim de plantas cultivadas em Petrópolis/RJ de $26,0 \%$ de cânfora, $22,1 \%$ de 1,8 cineol, $12,4 \%$ de mirceno e $11,5 \%$ de alfa-pineno.

A composição e os teores dos componentes do óleo, quantificadas através das análises cromatográficas realizadas no período experimental, estão quantificadas na Tabela 1, sendo que os teores médios dos componentes principais foram 10,$0 ; 4,8 ; 8,8 ; 3,9 ; 13,0 ; 26,0 ; 2,3 ; 3,4$ e 5,3\%, respectivamente para alfa-pineno, beta-pineno, mirceno, limoneno, 1,8-cineol, cânfora, alfaterpineol, verbenona e cariofileno. A escassez de informações em trabalhos que envolvam plantas medicinais, como o alecrim e também de outras espécies, principalmente devido ao alto custo de suas análises, dificultam a comparação entre a quantidade dos componentes expressos na Tabela 1 e os obtidos por outros autores.

\section{CONCLUSÃO}

Maiores intervalos entre cortes permitem que a planta fique mais alta, acumule maior quantidade de massa seca da parte aérea.

\section{REFERÊNCIA}

ADAMS, R.P. Identification of Essential Oils Components by Gas Chromatography/Mass Spectrometry. 2.ed. Carol Stream: Allured Publishing Corporation, 1995. 469p.

BLANCO, M.C.S.G. Preparado biodinâmico, épocas de colheita, temperaturas de secagem, tempo de armazenamento e tipos de embalagem na produção e conservação de alecrim (Rosmarinus officinalis L.). 2001. 76p. Tese (Doutorado - Área de Concentração em Horticultura) - Departamento de Produção Vegetal, Universidade Estadual Paulista, Botucatu.

CHALCHAT, J.C. et al. Essential oils Rosemary (Rosmarinus officinalis L.) the chemicals composition of oils of various origins (Morocco, Spain France). Journal of Essencial Oil Research, v.5, p.613-8, 1993.

CLEVENGER, J.F. Apparatus for the determination of volatile oil. Journal of American Pharmacological Association, v.17, p.345-9, 1928.

CORRÊA JÚNIOR, C.; MING, C.L.; SCHEFFER, M.C. Cultivo de plantas medicinais, condimentares e aromáticas. 2.ed. Jaboticabal: FUNEP, 1994. 162p.

CRUZ, G.F.; INNECCO, R.; MATTOS, S.H. Determinação 
da altura e número de cortes da alfavaca cravo. Horticultura Brasileira, v.19, n.2, supl., p.244, 2001. CZEPAK, M.P. Produção de óleo e mentol cristalizável em oito freqüências de colheita da menta (Mentha arvensis L.). 1995. 81p. Dissertação (Mestrado - Área de Concentração Fitotecnia) - Departamento de Produção Vegetal, Escola Superior de Agricultura Luiz de Queiroz, Piracicaba.

GUILLÉN, M.D.; CABO, N.; BURILLO, J. Characterization of the essential oils of some cultivated aromatic plants of industrial interest. Journal of the Science of Food and Agriculture, v.70, p.359-63, 1996.

MARTINS, E.R. et al. Plantas medicinais. Viçosa: UFV, 1998. 220p.

MOL, D.J.S. et al. Acúmulo da biomassa e rendimento de óleo essencial de carqueja em função de sistemas de manejo e alturas de corte. Horticultura Brasileira, v.20, n.2, supl.1, p.355, 2002.

PORTE, A. Estudos de óleos essenciais de três plantas condimentares da família Lamiacea. 2000. 216p. Dissertação (Mestrado - Área de Concentração Ciência dos Alimentos) - Departamento de Ciência e Tecnologia dos Alimentos - Universidade Federal Rural do Rio de Janeiro, Rio de Janeiro.

PORTE, A.; GODOY, R.L.O. Alecrim (Rosmarinus officinalis L.): propriedades antimicrobiana e química do óleo essencial. Boletim do Centro de Pesquisa e Processamento de Alimentos, v.19, n.2, p.193-210, 2001. ROBBINS, S.R.J.; GREENHALGH, P. The markets for select herbaceous essential oils. London: Tropical Products Institute, 1979. 60p.

SCHEFFER, M.C. Roteiro para estudos de aspectos agronômicos das plantas medicinais selecionadas pela fitoterapia do SUS-PR/CEMEPAR. SOB Informa, v.9/10, n.2, p.29-31, 1992.

SOLIMAN, F.M. et al. Analysis and biological activity of the essential oil of Rosmarinus officinalis from Egypt. Flavour and Fragrance Journal, v.9, n.1, p.29-33, 1994.

VAN RAIJ, B. et al. Análise química para avaliação da fertilidade de solos tropicais. Campinas: IAC, 2001. $285 p$.

ZEGARSKA, Z. et al. Antioxidative effect of Rosemary ethanolic extract on butter. Milchwissenschaft, v.51, p.195-8, 1996. 